\title{
Exploiting Genetic Diversity for Blast Disease Resistance Sources in Finger Millet (Eleusine coracana)
}

\author{
Eric O. Manyasa, ${ }^{1,2,+}$ Pangirayi Tongoona, ${ }^{2}$ Paul Shanahan, ${ }^{2}$ Stephen Githiri, ${ }^{2}$ Henry Ojulong, ${ }^{1}$ and Samuel M. C. Njoroge ${ }^{3}$ \\ ${ }^{1}$ International Crops Research Institute for the Semi-Arid Tropics (ICRISAT), Nairobi 00623, Kenya \\ ${ }^{2}$ School of Agricultural, Earth and Environmental Sciences, University of KwaZulu-Natal, Scottsville, Pietermaritzburg 3209, South Africa \\ ${ }^{3}$ ICRISAT, Lilongwe, Malawi
}

Accepted for publication 11 July 2019.

\section{Abstract}

Finger millet blast, caused by Magnaporthe grisea, is the most important disease of finger millet in East Africa. Diseased plants are significantly less productive, and most cultivars grown by farmers are susceptible to the disease. Fungicide application is an option for disease management; however, smallholder farmers cannot afford the cost. Host plant resistance is therefore the most viable option for managing the disease. Eighty-one finger millet germplasm accessions from East Africa were evaluated for resistance to blast disease, in natural and inoculated trials. Three accessions (G18, G43, and G67) were identified as resistant to all the three progressive stages of blast: leaf, neck, and panicle. However, one (G3) and four $(\mathrm{G} 15, \mathrm{G} 16, \mathrm{G} 60$, and $\mathrm{G} 70)$ accessions were only resistant to leaf and neck blast, respectively. Two resistant (G39 and G43) and 12 moderately resistant (G3, G7, G11, G20, G23, G27, G31, G33, G36, G66, G74, and G81) accessions to blast attained grain yields $>2.0 \mathrm{t} / \mathrm{ha}$. These accessions varied in time to maturity, plant height, and grain color, which will enable farmers to select accessions appropriate to their target agro-ecological zones and desired end uses. East African finger millet germplasm has high potential as a source of blast-resistant accessions that could be evaluated for direct production and/or for blast-resistance breeding.

Keywords: genetic diversity, finger millet, blast resistance, East Africa
In East Africa, finger millet (Eleusine coracana L.) is grown on over 800,000 ha: 470,000 ha in Uganda, 350,000 ha in Tanzania, and 77,890 ha in Kenya (ICRISAT 2013). Over the last 30 years, production of finger millet has increased by $25 \%$ in response to domestic demand, coupled with increased regional trade and higher market prices (Lenné et al. 2007). Finger millet is mainly consumed as a stiff porridge (also called ugali in the local language, Kiswahili) or thin porridge (uji) and is used to make local beer. Value addition of finger millet grain into flour has also contributed to increases in consumption as breads and cakes. The grain is high in calcium (358 $\mathrm{mg} / \mathrm{kg}$ ), iron (46 mg/kg), and protein $(7.4 \%)$ and has good digestibility (NRC 1996; Serna-Saldivar and Rooney 1995), which makes it an important food for expectant women, breast-feeding mothers, children, the sick, and diabetics.

Several constraints inhibit the crop's potential productivity. There is a limited understanding and utilization of the genetic diversity of the region's germplasm, a lack of high-yielding improved cultivars, high prevalence of finger millet blast caused by Magnaporthe grisea (Herbert) Barr, poor crop husbandry, infestation by striga (Striga hermonthica [Del.] Benth.), and lack of policy support (Sreenivasaprasad et al. 2007).

${ }^{\dagger}$ Corresponding author: E. O. Manyasa; E-mail: E.Manyasa@cgiar.org

Funding: This study was carried out with financial support from the Bill and Melinda Gates Foundation through the Harnessing Opportunities for Productivity Enhancement of Sorghums and Millets (HOPE) project.

The author(s) declare no conflict of interest.

(C) 2019 The American Phytopathological Society
Finger millet is mainly grown in the subhumid to humid zones of Lakes Victoria and Tanganyika, where blast thrives. Blast is the most important disease of finger millet in East Africa and causes yield losses of between 10 and 68\% (Takan et al. 2004). Owing to the favorable weather and presence of alternate host plants (wild grasses) in the region, the disease occurs throughout the year (Mackill and Bonman 1992; Pande et al. 1995). Finger millet blast disease initially appears as lesions on the leaves. In susceptible plants, the lesions expand rapidly and coalesce, leading to complete drying of infected leaves. When the neck is infected, all parts above the infected section may die (Sreenivasaprasad et al. 2004), causing yield loss owing to inhibited grain formation or shriveled grain. In such cases, yield losses may be as high as 90\% (Ekwamu 1991). The panicle phase of the disease (also known as finger blast) is the most destructive, causing nonformation of grain or poorly filled shriveled grain (Takan et al. 2012). One, several, or all fingers on the panicle could be affected. Most cultivars grown by farmers are susceptible to the disease, and although fungicides for the control of the disease are available, they are expensive and unaffordable to farmers relative to the economic returns from finger millet (Sunil and Anilkumar 2003). Host plant resistance therefore remains the most viable option in the management of the disease. Improved cultivars available in the region have mainly been bred from local germplasm selections (Oduori 2008). This study was conducted to evaluate the blast reaction of 81 finger millet germplasm lines selected from an East African germplasm pool.

\section{Screening for Resistance}

A total of 81 accessions (Table 1), with potential for high productivity, and blast resistance were selected from 420 accessions 
(340 landraces and 80 global minicore set) previously phenotyped across four locations in Kenya (Manyasa 2013; Manyasa et al. 2015). The minicore comprises $1 \%$ of the global collection at International Crops Research Institute for the Semi-Arid Tropics (ICRISAT) GeneBank representing the total global diversity (Upadhyaya et al. 2010). Five checks were also included: (i) resistant G78 = KNE 814 (ii) moderately resistant G80 = U 15; (iii) high-yielding and moderately resistant G81 = Kahulunge; (iv) susceptible G77 = KNE 479; and (v) high-yielding and moderately resistant G79 = Nakuru FM 1.
The accessions were evaluated at the Kenya Agricultural Livestock Research Organization/ICRISAT research station in Alupe, western Kenya. The station lies at latitude $0^{\circ} 28^{\prime} \mathrm{N}$, longitude $34^{\circ} 7^{\prime} \mathrm{E}$, and $1,189 \mathrm{~m}$ above sea level; it receives a mean annual rainfall of $1,100 \mathrm{~mm}$ and has a mean annual temperature of $24^{\circ} \mathrm{C}$. During the year, farmers grow crops during the bimodal rainfall season: the "long rains" from March to June and the "short rains" from September to December.

The trials were planted in a $9 \times 9$ square lattice design with two replications per trial. Each experimental plot comprised three 4-m-long

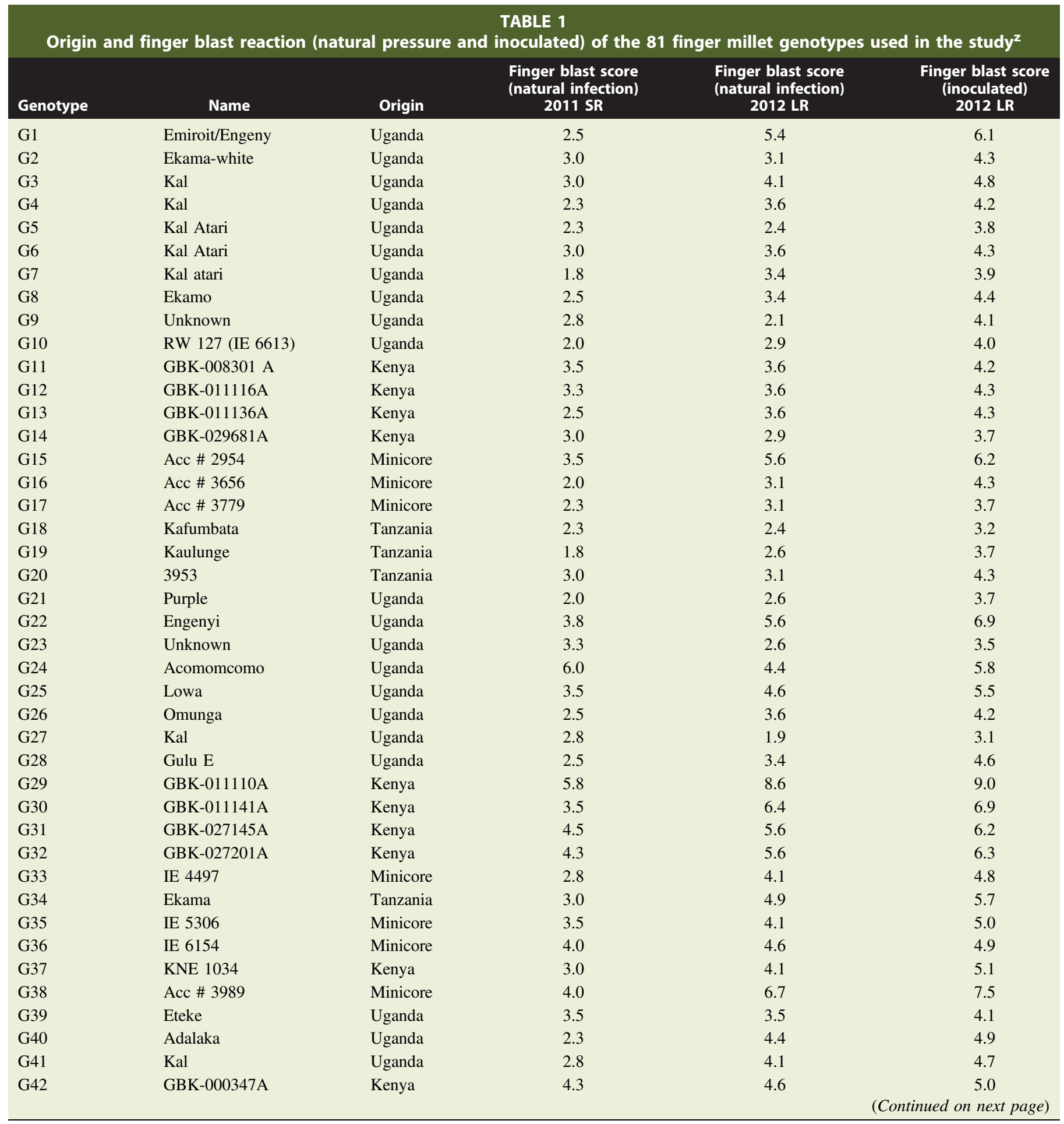

\footnotetext{
${ }^{\mathrm{z}} \mathrm{SR}=$ short rains, and $\mathrm{LR}=$ long rains.
} 
rows, with interrow and intrarow spacing of 0.4 and $0.1 \mathrm{~m}$, respectively. Seed was manually drilled in furrows and thinned at 2 weeks after emergence to 41 plants per row. Fertilizer application, weeding, and pest control were done according to recommended practices. Experiments were conducted under natural disease pressure for two seasons (2011 short rains and 2012 long rains) and under artificial inoculation for one season (2012 long rains).

For inoculation, we used a combination of infested crop debris, infector rows, and a sprayed spore suspension, followed by supplemental irrigation (Kiran Babu et al. 2013; Pande et al. 1995). An infector row (using susceptible line GBK-011118A) was planted after every six test rows. Infested finger millet debris collected from the previous season was spread in between test rows on moist soil (15 to 20 days after sowing). Inoculum for foliar spraying was prepared from a single-spore representative culture of $M$. grisea. This culture was isolated from blast-infected samples collected from the finger millet fields in the previous season at Alupe and grown on oatmeal agar medium at $26 \pm 1{ }^{\circ} \mathrm{C}$ for 10 days (Kiran Babu et al. 2013). Conidia were harvested by flooding the culture with sterilized distilled water, scraping the mycelia with a spatula to dislodge spores, and then collecting the solution into sterile falcon tubes. The conidial suspension was adjusted to $1 \times 10^{5}$ spores $/ \mathrm{ml}$ using a

\begin{tabular}{|c|c|c|c|c|c|}
\hline \multicolumn{6}{|c|}{$\begin{array}{c}\text { TABLE } 1 \\
\text { (Continued from previous page) }\end{array}$} \\
\hline Genotype & Name & Origin & $\begin{array}{c}\text { Finger blast score } \\
\text { (natural infection) } \\
2011 \mathrm{SR}\end{array}$ & $\begin{array}{c}\text { Finger blast score } \\
\text { (natural infection) } \\
2012 \text { LR }\end{array}$ & $\begin{array}{l}\text { Finger blast score } \\
\text { (inoculated) } \\
2012 \text { LR }\end{array}$ \\
\hline G43 & GBK-000351A & Kenya & 2.0 & 2.1 & 2.8 \\
\hline G44 & GBK-000368A & Kenya & 4.0 & 6.8 & 7.5 \\
\hline G47 & GBK-011111A & Kenya & 4.8 & 7.1 & 7.8 \\
\hline G48 & GBK-011129A & Kenya & 4.8 & 6.8 & 7.3 \\
\hline G49 & GBK-011133A & Kenya & 5.5 & 6.6 & 7.4 \\
\hline G50 & GBK-011137A & Kenya & 4.3 & 5.6 & 6.2 \\
\hline G51 & GBK-027149A & Kenya & 4.0 & 4.9 & 5.5 \\
\hline G56 & GBK-043163A & Kenya & 3.5 & 5.1 & 5.9 \\
\hline G57 & Acc \# 79 & Minicore & 3.5 & 3.6 & 4.4 \\
\hline G58 & Acc \# 3924 & Minicore & 4.0 & 6.6 & 7.3 \\
\hline G59 & Р 224 & Uganda & 2.5 & 3.6 & 4.8 \\
\hline G60 & Unknown & Uganda & 3.0 & 3.3 & 3.8 \\
\hline G61 & Etiyo-brown & Uganda & 2.5 & 1.6 & 2.1 \\
\hline G62 & Ekama & Uganda & 3.3 & 4.1 & 4.7 \\
\hline G63 & Kal & Uganda & 3.8 & 5.1 & 5.7 \\
\hline G64 & Otara chigal & Uganda & 2.8 & 3.1 & 4.5 \\
\hline G65 & GBK-000352A & Kenya & 2.8 & 4.6 & 5.6 \\
\hline G66 & GBK-011113A & Kenya & 2.8 & 3.6 & 4.0 \\
\hline G74 & IE 4121 & Minicore & 2.8 & 3.4 & 3.9 \\
\hline G75 & Ngome & Uganda & 3.5 & 4.1 & 4.5 \\
\hline G76 & Katila & Uganda & 2.0 & 2.6 & 3.3 \\
\hline G77 & KNE 479 & Kenya & 7.3 & 8.6 & 9.0 \\
\hline G78 & KNE 814 & Kenya & 1.8 & 1.8 & 2.4 \\
\hline G79 & Nakuru FM 1 & Kenya & 4.5 & 6.1 & 7.1 \\
\hline G80 & U 15 & Uganda & 3.3 & 5.9 & 6.6 \\
\hline G81 & Kahulunge & Tanzania & 2.5 & 2.6 & 3.3 \\
\hline Mean & & & 3.3 & 4.3 & 5.1 \\
\hline SE \pm & & & 0.78 & 0.580 & 0.64 \\
\hline CV\% & & & 23.7 & 12.9 & 19.4 \\
\hline $\mathbf{L S D}_{0.05}$ & & & 1.57 & 1.15 & 2.1 \\
\hline
\end{tabular}


hemocytometer, and the suspension was used to inoculate plants in the field at Alupe. Inoculation with the spore suspension was done by drenching 20-day-old seedlings and repeated at preflowering. The control experiment was sprayed with water alone (Kiran Babu et al. 2013). In addition, postinoculation irrigation was applied at least once a day on rain-free days, from 11 a.m. to 12 p.m., to increase humidity for disease development, up to the start of grain filling.

All blast disease data were recorded on five randomly selected plants, which were tagged in each plot. The leaf blast severity was recorded at 30,51, 61, and 71 days after sowing (coinciding with tillering, booting, flowering, and milky stages of most accessions) using a 1 to 9 scale (Pande et al. 1995). Neck blast severity was scored using a scale of 1 to 5 developed for finger millet at ICRISAT (Kiran Babu et al. 2013). Panicle blast severity was scored using a 1 to 9 disease rating scale (Pande et al. 1995). For neck and panicle blast, scoring was done at 61, 71, 81, 91, and 101 days after sowing, and these coincided, respectively, with flowering, milky, soft dough, hard dough, and physiological maturity stages of most accessions. Data were also recorded on days to flowering, plant height, and grain yield.

Analysis of variance for all quantitative data was done using Genstat 15.0 (https://vsni.co.uk). Because variance among the environments were found to be heterogeneous using the Bartlett test (Bartlett 1937), the genotype $\times$ environment data were transformed by subtracting the environment mean and dividing by standard errors of the corresponding environment.

Area under disease progress curve (AUDPC) was calculated for mean disease severity scores (up to milk-dough stage for leaf blast and up to physiological maturity for neck and panicle blast) for each genotype, as described by Wilcoxson et al. (1975). To compare AUDPC values from different experiments, the relative AUDPC (RAUDPC) values were calculated by dividing AUDPC by the duration of the epidemic (Ben-Noon et al. 2003). Spearman's rank correlations between traits were determined.

\section{Germplasm Performance}

The 2011 short rainy season received $439 \mathrm{~mm}$ of rainfall with minimum and maximum temperatures of 16.8 and $29.2^{\circ} \mathrm{C}$, respectively (mean $23.0^{\circ} \mathrm{C}$ ) and mean relative humidity of $84.2 \%$. The 2012 long rains had $546 \mathrm{~mm}$ of rainfall with minimum and maximum temperatures of 17.1 and $30.4^{\circ} \mathrm{C}$, respectively (mean $23.8^{\circ} \mathrm{C}$ ) and mean relative humidity of $78.6 \%$. Disease pressure was higher under artificial inoculation compared with noninoculated plots and in the long rainy season compared with the short rainy season. Comparing blast data for 2012 long rains (natural pressure) and 2012 long rains (artificial inoculation), inoculation increased disease severity by 12.9 to $40 \%$ for leaf blast, 0.0 to $52.8 \%$ for neck blast, and 5.0 to $95 \%$ for panicle blast. Lesions were first recorded on leaves of inoculated plants about 5 days earlier than in noninoculated plants. Lesions were initially small and water-soaked, and as the disease progressed the lesions developed into spindleshaped spots with a gray center and brown margin (Fig. 1). On susceptible accessions, the disease progressed, infecting the neck and panicle (Fig. 2A and B). Neck and panicle infections led to poor seed set and significantly reduced yield.

The disease progress rate on the leaf, neck, and panicle differed among accessions. Interestingly, the severity of leaf blast was relatively lower for accessions that were either resistant or susceptible to neck and panicle blast. Severity of neck blast of all susceptible accessions, including susceptible check G77, was higher than the severity for panicle blast in the same accessions. A sharp increase in panicle blast severity in the susceptible accessions was recorded between 61 and 81 days after sowing. At 110 days after sowing, all these susceptible lines had mean severity scores of 5.0 ( $>6.0 \mathrm{~cm}$ size lesions or $>70 \%$ severity) for neck blast.

For resistant accessions, neck blast progressed slowly. By 81 days after sowing, panicle blast severity in the most susceptible accessions was $>6.0(>30 \%$ ), whereas it was $<2.5$ (about $5 \%$ ) in the most resistant accessions. At 101 days after sowing, the six susceptible accessions had panicle blast severity scores $>7.0$ ( $>40 \%)$, with the two most susceptible accessions at the maximum severity score of $9.0(>80 \%)$. In the resistant accessions, the maximum panicle blast severity at 101 days after sowing was $<3.5(\leq 10 \%)$, with the most resistant accession (G61) attaining the lowest severity with a score of $<2.0(<5 \%)$ (Fig. 3).

All six susceptible accessions flowered early (59 to 64 days). The six resistant accessions were mostly pigmented, whereas the six highly susceptible types (which included susceptible check G77) were mostly tan colored. Susceptible accessions G38 and G77 exhibited reasonable levels of tolerance, attaining yields $>1.00 \mathrm{t} / \mathrm{ha}$ despite their high neck and panicle blast scores (Table 2). Resistance to blast has been linked to phenolic compounds found in pigmented plants (Jain et al. 1975; Seetharam and Ravikumar 1993) and to semicompact/compact panicle shape (Pande et al. 1995; Takan et al. 2004), which corroborates the predominance of pigmented plant types with semicompact and compact panicles among the resistant accessions detected in this study.

Grouped into resistant, moderately resistant, susceptible, and highly susceptible, the number of accessions that fell into these classes were $3,67,11$, and 0 , respectively, for leaf blast; 15 accessions were resistant, 37 moderately resistant, 21 susceptible, and 8 highly susceptible to neck blast; and 10 accessions were resistant, 56 moderately resistant, 9 susceptible, and 6 highly susceptible to panicle blast. The most resistant accessions were G18, G67, and

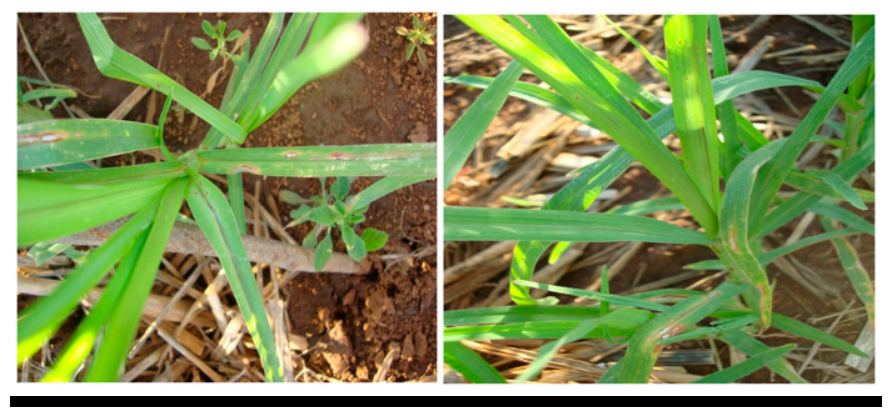

FIGURE 1

Leaf blast symptoms on seedlings 10 days after inoculation.

A

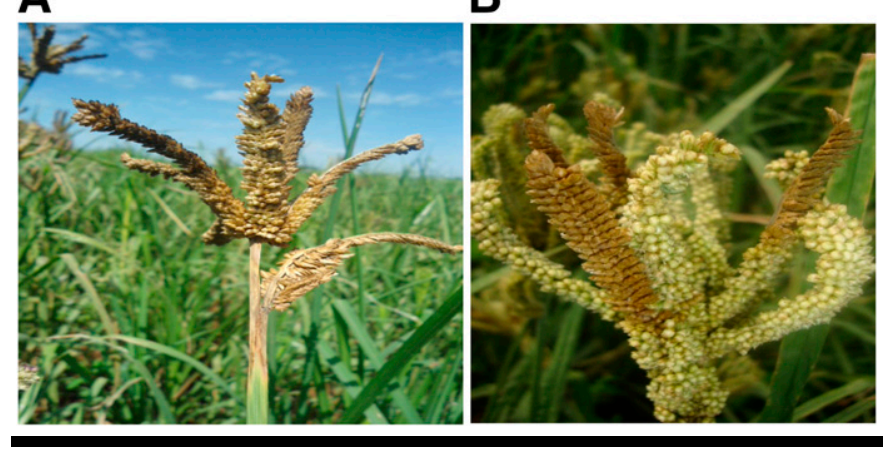

FIGURE 2

A, Neck and panicle blast; B, fingers blasted. 
G43 for all three blast types; G9, G7, G8, G2, and G6 for leaf and neck blast; and G27, G78, G76, and G81 for neck and panicle blast. Accession G3 presented high resistance to leaf blast only, whereas G16, G15, G60, and G70 had high resistance to neck blast only.

AUDPC was highly significant $(P \leq 0.01)$ for the three blast types. In most cases, resistant accessions had lower RAUDPC values for all the three blast types, with higher values recorded in

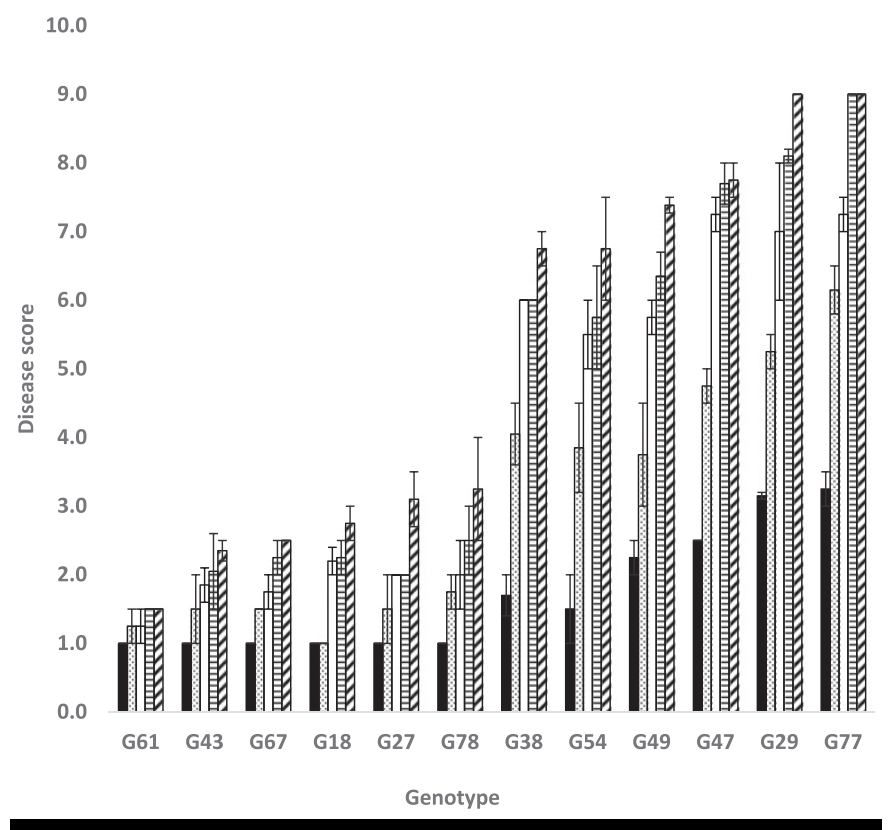

FIGURE 3

Progression of finger millet blast in select genotypes characterized as resistant and susceptible. Bar graphs with solid black fill, dotted fill, no fill, horizontal fill, and slanted line fill represent scores taken at 61, 71, 81, 91, and 101 days after planting, respectively. Error bars represent 1 standard error of the mean. susceptible accessions; however, lower values were not always significantly different (Table 2).

\section{Correlation to Other Important Traits}

Based on Spearman's rank correlation, leaf, neck, and panicle blast had significant $(P \leq 0.05)$ negative correlation with grain yield ( $r=-0.233,-0.481$, and -0.486 , respectively), with days to flowering ( $r=-0.431,-0.381$, and -0.440 , respectively), and with panicle shape ( $r=-0.201,-0.192$, and -0.189 , respectively). Although not significant, plant color was also negatively correlated with neck blast $(r=-0.012)$ and panicle blast $(r=-0.134)$. Highly significant $(P \leq 0.01)$ positive correlations between leaf and neck $(r=0.436)$, leaf and panicle $(r=0.458)$, and neck and panicle $(r=$ $0.754)$ blast were recorded.

Results of this study agree with those reported by Ou and Nuque (1963), who found positive correlations between leaf, neck, and panicle blast. They also reported that some resistant accessions to neck and panicle blast were agronomically superior but had higher leaf blast AUDPC values. Bonman et al. (1989) also reported a few cases in rice in which cultivars susceptible to leaf blast exhibited resistance to neck blast and attributed this to nonlinkage of leaf and neck blast resistance in the cultivars involved. Therefore, using leaf blast to select for neck and panicle blast resistance should be done with caution. Because the scores for the three blast types were highly correlated in most of the accessions in this study, the high AUDPC, RAUDPC, and blast severity scores at physiological maturity when blast severity is at maximum indicate the possibility of a single selection at this growth stage for all the three blast types in finger millet.

Because the most vulnerable stage for neck and panicle blast in finger millet is at the preflowering stage, high inoculum levels early in the season could be the cause of high susceptibility in early flowering accessions, as reported by Kiran Babu et al. (2013) and Esele (2002). The negative correlation between the three blast types with grain yield was owing to reduced photosynthetic area on affected leaves, poor or no nutrient flow to the panicle when necks are affected, and poor grain filling and sterility owing to both neck and panicle infection. All these elements led to reduced grain yield.

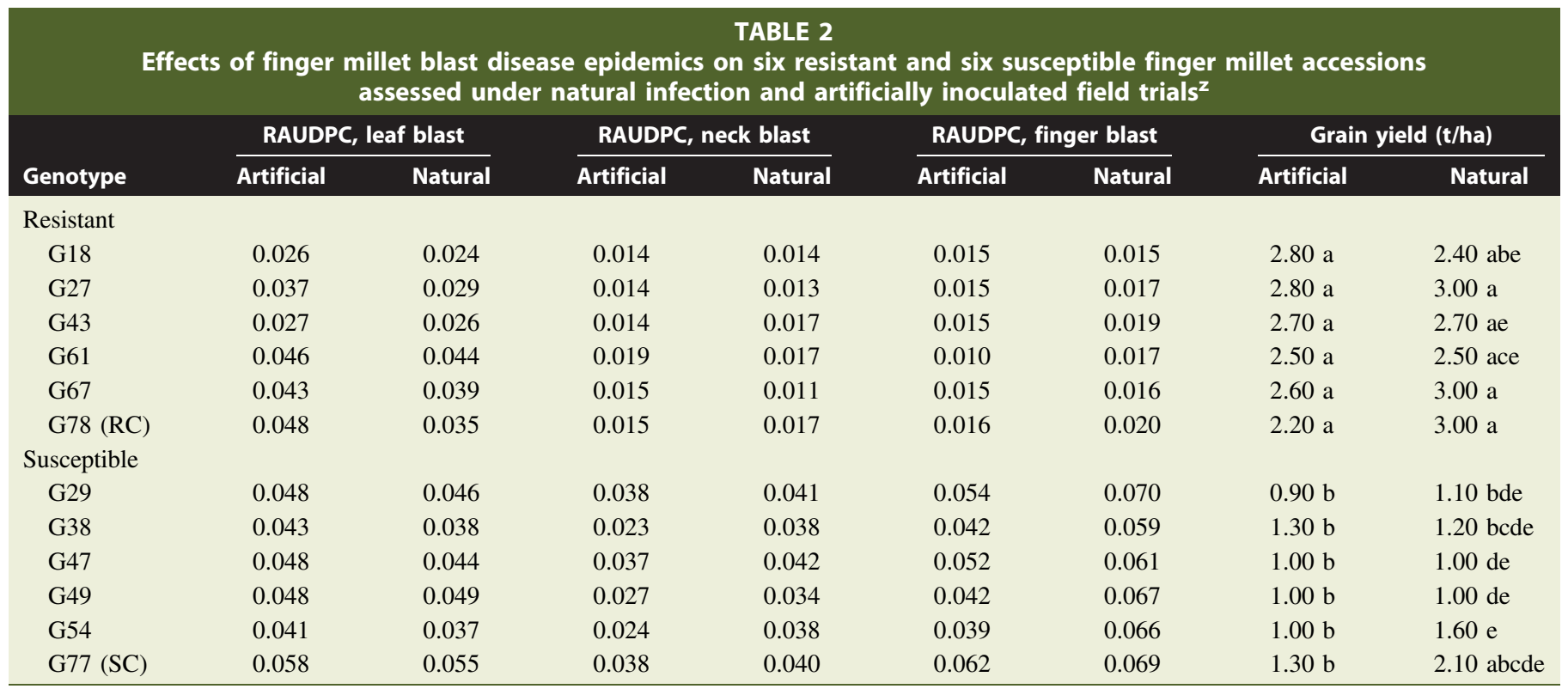

${ }^{\mathrm{z}}$ Relative area under the disease progress curve (RAUDPC) was calculated from mean disease severity scores (up to milk stage for leaf disease on a 1 to 9 scale, up to physiological maturity for neck blast on a 1 to 5 scale, and finger blast on a 1 to 9 scale). $\mathrm{RC}=$ resistant check; and SC $=$ susceptible check. 
Similar observations were also reported by Rath and Mishra (1975) and Takan et al. (2004).

\section{Recommendations}

Although we recorded significant variability in infection among the accessions, over $50 \%$ showed resistance to leaf, neck, and panicle blast under artificial inoculation. Accessions with low and moderate blast scores recorded the highest grain yield, whereas the most susceptible accessions flowered early and had low grain yield. No genotype was completely immune to blast. Blast-resistant accessions had diversity in plant height, days to flowering, grain yield, and grain color, which will provide farmers with options to select for their target agro-ecologies and end uses. Early maturing varieties grown by farmers are susceptible to blast (E. Manyasa, personal observation); therefore, growing relatively early and medium maturity and blast-resistant accessions identified in this study (G39, G43, G27, G16, and G60) should result in increased finger millet productivity. In addition, accessions G18, G43, and G67 with high resistances to the three blast types and accessions G27, G78, G76, and G81 with resistance to both neck and panicle blast were also identified. These resistant accessions will be useful parents in breeding new lines with blast resistance and high grain yield.

The existence of pathogenic races of $M$. grisea has been reported between seasons in rice (Nelson 1973) and between agro-ecological zones in finger millet (Sreenivasaprasad et al. 2005). It is therefore essential that these accessions are adequately screened for blast across seasons and agro-ecological zones to ascertain stability of their resistance, especially in humid and subhumid finger millet production areas where blast is prevalent. Owing to reported pathogen variability and appearance of pathotypes initially confined to Asia and East Africa (Takan et al. 2012), there is also a need for regular monitoring of the pathogen populations. This will enable the breeders and pathologists to determine if new pathotypes have been introduced into the region and if the frequencies of certain pathotypes change over time, so they can then design appropriate breeding approaches.

\section{Conclusions}

Disease severity scores were highly negatively correlated with days to flowering and grain yield, suggesting that early lines suffer more disease damage leading to reduced yield. The slow blast resistance recorded in the identified accessions in this study may provide more durable resistance, given the high variability associated with the blast pathogen. Qualitative traits such as plant color and panicle shape that were found associated with blast resistance could be useful as selectable markers in early breeding generations. Accessions G43, G39 (resistant), G33, G20, G66, G23, G81, G7, G27, G31, G74, G11, G36, and G3 (moderately resistant) with yields above $2.00 \mathrm{t} / \mathrm{ha}$ will be further evaluated for direct commercialization, whereas accessions G61, G67, G70, G18, G16, G60, G27, and $\mathrm{G} 78$ have potential for use as sources of resistance to blast.

\section{Acknowledgments}

The authors thank Patrick Sheunda, Daniel Ajaku, and Joseph Kibuka for their assistance in managing field trials.

\section{Literature Cited}

Bartlett, M. S. 1937. Properties of sufficiency and statistical tests. Proc. R. Soc. London A 160:268-282

Ben-Noon, E., Shtienberg, D., Shelvin, E., and Dinoor, A. 2003. Joint action of disease control measures: A case study of Alternaria leaf blight of carrot. Phytopathology 93:1320-1328.
Bonman, J. M., Estrada, B. A., and Bandong, J. M. 1989. Leaf and neck blast resistance in tropical lowland rice cultivars. Plant Dis. 73:388-390.

Ekwamu, A. 1991. Influence of head blast infection on seed germination and yield components of finger millet (Eleusine coracana L. Gaertn). Trop. Pest Manage. 37:122-123.

Esele, J. P. E. 2002. Disease of finger millet: A global review. Pages 19-26 in: Sorghum and Millets Diseases. J. F. Leslie, ed. Iowa State Press, Ames, IA.

ICRISAT. 2013. Finger Millet Strategic Plans: Ethiopia, Kenya, Tanzania and Uganda, 2012-2016. Harnessing Opportunities for Productivity Improvement of Sorghum and Millet (HOPE) Project Report. ICRISAT, Nairobi, Kenya.

Jain, K. S., Quaset, C. O., Bhatt, G. M., and Wu, K. K. 1975. Geographical patterns of phenotypic diversity in a world collection of durum wheat. Crop Sci. 15:700-704

Kiran Babu, T., Thakur, R. P., Upadhyaya, H. D., Reddy, P. N., Sharma, R., Girish, A. G., and Sarma, N. D. R. K. 2013. Resistance to blast (Magnaporthe grisea) in a mini-core collection of finger millet germplasm. Eur. J. Plant Pathol. 135:299-311.

Lenné, J. M., Takan, J. P., Mgonja, M. A., Manyasa, E. O., Kaloki, P., Wanyera, N., Okwadi, J., Muthumeenakshi, S., Brown, A. E., Tamale, M., and Sreenivasaprasad, S. 2007. Finger millet blast disease management: A key entry point for fighting malnutrition and poverty in East Africa. Outlook Agric. 36:101-108.

Mackill, D. J., and Bonman, J. B. 1992. Inheritance of blast resistance in nearisogenic lines of rice. Phytopathology 82:746-749.

Manyasa, E. O. 2013. A Study of the Diversity, Adaptation and Gene Effects for Blast Resistance and Yield Traits in East African Finger Millet (Eleusine coracana (L.) Gaertn) Landraces. Ph.D. thesis. University of KwaZulu Natal, Durban, South Africa.

Manyasa, E. O., Tongoona, P., Shanahan, P., Mgonja, M. A., and de Villiers, S. 2015. Genetic diversity in east African finger millet (Eleusine coracana (L.) Gaertn) landraces based on SSR markers and some qualitative traits. Plant Genet. Resour. 13:45-55.

National Research Council. 1996. Finger millet. Pages 39-57 in: Lost Crops of Africa, Volume I: Grains. National Academy of Sciences, Washington, DC.

Nelson, R. R. 1973. Pages 94-101 in: Breeding Plants for Disease Resistance: Concepts and Applications. Pennsylvania State University, State College, PA.

Oduori, C. O. A. 2008. Breeding Investigations of Finger Millet Characteristics Including Blast Disease and Striga Resistance in Western Kenya. Ph.D. thesis, University of KwaZulu Natal, Durban, South Africa.

Ou, S. H., and Nuque, F. L. 1963. The relation between leaf and neck resistance to the rice blast disease. Int. Rice Comm. Newsl. 12:30-35.

Pande, S., Mukuru, S. Z., King, S. B., and Karunakar, R. I. 1995. Biology of, and resistance to finger millet blast in Kenya and Uganda. In: Eighth EARSAM Regional Workshop on Sorghum and Millets, 30 Oct. - 5 Nov 1992, Wad Medani, Sudan. S. Z. Mukuru and S. B. King, eds. International Center for Agricultural Research in the Semi-Arid Tropics, Patancheru, India.

Rath, G. C., and Mishra, D. 1975. Nature of losses due to neck blast infection in ragi. Sci. Cult. 41:322-323.

Seetharam, A., and Ravikumar, R. L. 1993. Blast resistance in finger millet, its inheritance and biochemical nature. Pages 449-467 in: Advances in Small Millets. K. W. Riley, S. C. Gupta, A. Seetharam, and J. N. Mushonga, eds. Oxford and IBH, New Delhi, India.

Serna-Saldivar, S., and Rooney, L. W. 1995. Structure and chemistry of sorghum and millets. Pages 69-124 in: Sorghum and Millets: Chemistry and Technology. D. A. V. Dendy, ed. American Association of Cereal Chemists, St. Paul, MN.

Sreenivasaprasad, S., Takan, J. P., Mgonja, M. A., Manyasa, E. O., Kaloki, P., Wanyera, N. M., Okwadi, J., Muthumeenakshi, S., Brown, A. E., and Lenne, J. M. 2005. Enhancing finger millet production and utilisation in East Africa through improved blast management and stakeholder connectivity. Pages 11-22 in: Pathways Out of Poverty, Aspects of Applied Biology 75. D. Harris, J. I. Richards, P. Siverside, A. F. Ward, and J. R. Witcombe, eds. Association of Applied Biologists, Wellesbourne, U.K.

Sreenivasaprasad, S., Takan, J. P., Muthumeenakshi, S., Obilana, A. B., Manyasa, E. O., Audi, P. O., Oduori, C. A., Coll, R., Brown, A. E., Talbot, N. J., and Bandyopadhyay, R. 2007. Finger millet blast in E. Africa: Pathogen diversity and disease management. Pages 34-45 in: Proceedings of the First International Finger Millet Stakeholder Workshop, Projects R8030 and R8445 UK Department for International Development - Crop Programme held 13-14 Sept. 2005 at Nairobi. M. A. Mgonja, J. M. Lenné, E. Manyasa, and S. Sreenivasaprasad, eds. ICRISAT, Patancheru, India.

Sreenivasaprasad, S., Takan, J. P., Obilana, A. B., Manyasa, E., Brown, A. E., Bandyopadhyay, R., and Muthumeenakshi, S. 2004. Page 118 in: Finger Millet Blast in East Africa: Pathogen Diversity and Disease Management Strategies. Final Technical Report, R8030. DFID-CPP, London, U.K. 
Sunil, M. B., and Anilkumar, T. B. 2003. Components of slow blasting resistance in finger millet. Int. Sorghum Millets Newsl. 44:164-166.

Takan, J. P., Akello, B., Esele, J. P., Manyasa, E. O., Obilana, B. A., Audi, O. P., Kibuka, J., Odendo, M., Oduori, C. A., Ajanga, S., Bandyopadhyay, R., Muthumeenakshi, S., Coll, R., Brown, A. E., Talbot, N. J., and Sreenivasaprasad, S. 2004. Pathogen diversity and management of finger millet blast in East Africa: A summary of project activities and outputs. Int. Sorghum Millets Newsl. 45:66-69.

Takan, J. P., Chipili, J., Muthumeenakshi, S., Talbot, N. J., Manyasa, E. O., Bandyopadhay, R., Sere, Y., Nutsugah, S. K., Talhinhas, P., Hossain, M.,
Brown, A. E., and Sreenivasaprasad, S. 2012. Magnaporthe oryzae populations adapted to finger millet and rice exhibit distinctive patterns of genetic diversity, sexuality and host interaction. Mol. Biotechnol. 50: 145-158.

Upadhyaya, H. D., Yadav, D., Dronavalli, N., Gowda, C. L. L., and Singh, S. 2010. Mini core germplasm collections for infusing genetic diversity in plant breeding programs. Electron. J. Plant Breed. 1:1294-1309.

Wilcoxson, R. D., Skovmand, B., and Atif, A. H. 1975. Evaluation of wheat cultivars for ability to retard development of stem rust. Ann. Appl. Biol. 80: $275-281$ 